\title{
Effect of Different Substrates on the Production of Ganoderma lucidum (Curt.:Fr.) Karst.
}

\author{
O.K. Gurung ${ }^{1 *}$, U. Budathoki ${ }^{2}$ and G. Parajuli ${ }^{3}$ \\ ${ }^{1}$ Shree Punya Higher Secondary School, Rajarani 6, Dhankuta \\ ${ }^{2}$ Central Department of Botany, T.U., Kirtipur, Kathmandu \\ ${ }^{3}$ Plant Pathology Division, NARC, Khumaltar, Lalitpur \\ *E-mail: om.mss61@gmail.com
}

\begin{abstract}
In this study, the effects of various kinds of sawdust and supplements on the yield of Ganoderma lucidum were investigated in artificial cultivation. The sawdust of Alnus nepalensis, Shorea robusta and Dalbergia sisoo and supplements of rice bran, wheat bran, corn flour and gram flour were used as substrates in Ganoderma lucidum cultivation. Sawdust alone was used in control as a substrate media in the cultivation. Significant differences $(\mathrm{P}<0.05)$ were found among varieties of sawdusts and supplements. Similarly significant differences $(\mathrm{P}<0.05)$ were found in sawdust with supplements and without supplements in yield and biological efficiency. Dalbergia sisoo sawdust could not give yield in ambient condition; Shorea robusta gave very low yield and biological efficiency. Alnus nepalensis gave good yield and biological efficiency compared to the other sawdust.The highest yield and Biological efficiency were obtained from gram flour compared to the other brans. Alnus nepalensis sawdust supplemented with gram flour showed higher yield among all treatments. Supplementation showed positive role in mycelia growth and yield of mushroom.
\end{abstract}

Key words: Biological efficiency,suppliments, cultivation, Ganoderma lucidum, sawdust, substrate, yield

\section{Introduction}

Mushrooms are the fruiting bodies of macrofungi. Mushroom cultivation has become one of the most profitable agribusiness that could produce food products from different substrates and help to dispose them in an environmentally friendly manner (Bano et al., 1993). Red mushroom (Ganoderma lucidum) is a medicinal mushroom. Ganoderma lucidum (Curt.Fr.) P. Karst. ( Lingzhi in Chinese; Reishi, mannentake, or Sachitake in Japanese; and Youngzi in Korian) is a species of Class Basidiomycetes, which belongs to the family Polyporaceae or Ganodermataceae of the order Aphylophorales (Chang and Miles, 2004).
Ganoderma lucidum contains Triterpenes triterpenoids, polysaccharides, aminoacids , fungal immunomodulatory proteins and steroids. Several triterpenes, eg. ganoderans A,B and C, isolated from G.lucidum fruit bodies have been shown to have a strong hypoglycemic effect (Chang and Miles, 2004). All parts of Ganoderma lucidum, such as spore, mycelium and basidiocarp, are used for health purpose. For pharmaceutical purposes, a medicinal mushroom were almost always prepared either as hot water extracts, concentrate or in powdered form (Smith et al., 2002). The amount of wild Ganoderma is inadequate and unsafe to consume as insects and snakes 


\section{O.K. Gurung, U. Budathoki and G. Parajuli / Our Nature (2012) 10: 191-198}

make the mushroom poisonous; its cultivation is essential to meet the demand. In this connection, the techniques of cultivation have been developed and described during the last 15-20 years. Especially many workers have attempted to obtain agent ingredients by extraction from mycelium using submerged culture. Nowadays most of the medicinal mushrooms have been subjected to large scale artificial cultivation by solid substrate or low moisture fermentation. Mushroom cultivation is the only large scale biotechnological process that creatively utilizes lignocellulosics (Staments, 2000). Ganoderma lucidum has been cultivated by using several different substrates and by maintaining growth parameters such as temperature, relative humidity, water content, air pH and light intensity (Chang and Miles, 2004). Ganoderma lucidum is traditionally cultivated in solid culture to obtain fruiting body or basidiocarp and spawn is prepared using substrates such as grain, saw dust or wood. The advantage of SSF (solid state fermentation) over other techniques is that a concentrated product can be obtained from a cheap substrate, such as an agricultural residue with little pretreatment or enrichment (Wagner et al.,2003). This method of production has also several disadvantages, including the long time required to cultivate the fruiting body of Ganoderma lucidum, the difficulty of controlling the quality of the product, and the ease with which the culture is affected by the environmental changes. Recently, submerged fermentation technology for mycelial cultures of $G$. lucidum has been developed which none of the weaknesses has stated above (Yang and Lieu, 1998; Lee et al., 1999). The historical method of cultivation of medicinal mushrooms, and still practiced mainly in Asia, is on logs of broad leaved hardwood trees. The rapid worldwide cultivation of medicinal mushrooms is largely due to the use of polypropylene bags or containers.

Ganoderma lucidum grows on a wide variety of dead or dying trees, eg. Deciduous trees, especially Quercus, Acer, Alnus, Betula, Pyrus, Magnolia, etc. Currently, the methods most widely adopted for commercial production are the wood log, short wood segment, tree stump, sawdust bag and bottle procedures (Wasser, 2005).

For the cultivation of most medicinal mushrooms the basic substrate is hardwood sawdust( a mixture of fine and coarse sawdust to ensure good aeration) $75-80 \%$, supplemented with wheat bran $20 \%$ gypsum $1 \%$, sucrose $1 \%$, moisture content $60-65 \%$ and $\mathrm{pH}$ 5.5- 6.5. A successful artificial cultivation has been reported on solid substrates utilizing sawdust and different agricultural wastes (rice bran, wheat bran, sugarcane bagasse, rice husks, coconut fiber, peanut hulls, banana leaves etc). Tea waste was investigated by Peksen and Yakupoglu (2009), and it was concluded that tea waste can be used as a supplement for substrate preparation in G. lucidum cultivation. Erkel (2009) investigated the effect of three kinds of saw dusts (poplar, oak and beech) and brans (Wheat, rice and corn) on the yield of G. lucidum. The highest yield and biological efficiency were obtained from oak sawdust compared to the other sawdusts and also from wheat bran compared to the other supplements.

In Nepal, $G$. lucidum had been cultivated in 2004 AD in Nepal Agricultural Research Council taking four different types of substrate composition (sample A (saw dust $90 \%$, rice bran $10 \%$ ), sample $\mathrm{B}$ 


\section{O.K. Gurung, U. Budathoki and G. Parajuli / Our Nature (2012) 10: 191-198}

(sawdust $72 \%$, Corn meal $20 \%$, rice bran $7.8 \%, \mathrm{CaCO}_{3} 0.2 \%$ ), sample $\mathrm{C}$ (sawdust $90 \%$, Wheat bran 12\%) and sample $\mathrm{D}($ sawdust $90 \%$, wheat bran 10\%). 65-70\% moisture was adjusted in all four samples. The result showed that the above mentioned composition can be substrate for cultivation of G. lucidum (Plant Pathology Division, 2007). Similarly, paddy straw was used in Plant Pathology Division Nepal Agricultural Research Council) and the result showed that paddy straw is also one of the substrate for cultivation of Ganoderma lucidum. In the same year two strains (Japanese strain and Philippines strain) of G. lucidum were introduced for studying on log of Alder (Alnus nepalensis) and found biological efficiency of Japanese strain was higher than that of Philippines strain. However after the first flush the logs inoculated with Japanese strain were contaminated with other pathogens. Hence, the experiment needs to conduct in next time to conform the efficiency of these two strains in Alder logs (Plant Pathology Division, 2010).

\section{Materials and methods}

The research activities of the present study were carried out in the laboratory of Plant Pathology Department of Nepal Agricultural Research Council, Khumaltar lalitpur Nepal. The sawdusts were collected from different saw mill of Lalitpur district and supplements were collected from rice mills and other shops. The spawn of Ganoderma lucidum was brought from Centre for Agricultural Technology (CAT), Imadole, Lalitpur, Nepal. The study was conducted in June to September 2010.

The experiment was carried out with three kinds of sawdust including Alnus nepalensis (AS), Shorea robusta (SS), Dalbergia sisoo (DS), in control and with four kinds of supplements including rice bran (RB), wheat bran (WB), corn flour $(\mathrm{CF})$, gram flour (GF). The sawdust was used with different supplements as well as in controlled condition (without supplements) as artificial medium materials. The sawdust and supplement were mixed at a ratio of 9:1 based on their dry weight (W/W). No chemical constituents of media used in the fifteen treatments were determined. Moisture content of mixtures was adjusted approximately 60-65 \% with the help of moisture analyzer and palm test method before sterilization (Kwon and Kim, 2004). $\mathrm{No} \mathrm{CaCO}_{3}$ and gypsum were added to stabilize $\mathrm{pH}$ of the substrates. The $\mathrm{pH}$ of each treatments were measured with litmus paper and all showed approximately 5.56.5.

The substrates were packed into the polypropylene bags and plugged with cotton plug. Then the substrate bags were autoclaved at $121^{\circ} \mathrm{C}$ for $1.5 \mathrm{hrs}$. After cooling, sterilized bags were inoculated in the laminar air flow cabinet and incubated in dark incubation room. The temperature of the incubation room was maintained with the help of fan. The temperature was recorded during the incubation period regularly and was $28-30^{\circ} \mathrm{C}$. The substrates were kept in the incubation room till full colonization of the mycelium. When the mycelium had colonized on the substrate completely, the bags were shifted to cropping room [ room having high temperature i.e $30-32^{\circ} \mathrm{C}$, high humidity and light exposure] for the formation of fruiting bodies. The mouth of the bags were opened and kept on metal tray containing water to make high humidity. In growth stage frequent watering should be done in order to raise relative humidity approx. $80-90 \%$. 
Primordial formation of Ganoderma lucidum initiated in different days in different treatments. Fruiting bodies were harvested when the caps became completely red and the white margin disappeared. The total yield for each treatment was measured from two flushes in a harvest period of 75 days. The colonization period, primordial formation days and first harvest period were recorded and compared for all treatments. The biological efficiency (BE) percentage of fresh weight of harvested mushrooms/dry matter content of the substrate $\times 100$ was calculated (Royse, 1985). Experimental design was a Completely Randomized Design (CRD) with four replicates. The data were analyzed by using the analysis of variance (ANOVA) and group means were compared by Duncan Multiple Range Test (DMR) using the SPSS computer program (Version 16.0).

\section{Results and discussion}

Colonization period, primordial formation and first harvest days

There was equal colonization period (35 days) of Shorea robusta saw dust supplemented with gram flour, wheat bran, corn flour and rice bran (Fig.1). The colonization period of Shorea robusta in control could not be obtained due to slow mycelial growth and it was contaminated with other mould and discarded (Fig. 1).

The average primordial formation period for Shorea robusta sawdust with supplements was longer (46.0 days) than that of Alnus nepalensis. The primordial formation period for Alnus nepalensis in control was found 43 days.

The primordial formation period for Alnus nepalensis with supplements were found 40 days (Fig. 2). The primordia matured in 20 days in both Shorea robusta and Alnus nepalensis sawdust except for Alnus nepalensis sawdust in control 17 days.

The average first harvest days for Shorea robusta were found 66 days. The average first harvest of Alnus nepalensis sawdust with different supplement and control were found 60 days. Alnus nepalensis showed shorter period than that of Shorea robusta saw dust (Fig.3). In this experiment, the colonization period, primordial formation period and first harvest days for Dalbergia sisoo could not be obtained due to very poor mycelial growth.

\section{Effect of different type of sawdust on yield and $B E$}

Sawdust is the main ingredient used in substrate mixtures for Ganoderma lucidum cultivation. To investigate the feasibility of using three kinds of sawdusts as basal substrates, Shorea robusta, Dalbergia sisoo and Alnus nepalensis sawdust were tested with wheat bran, gram flour, rice bran, corn flour as supplements and sawdust alone. The highest yield of $15.05 \mathrm{~g} / 400 \mathrm{gm}$ and BE of $15.69 \%$ were obtained from Alnus nepalensis sawdust, and followed by Shorea robusta $(1.5 \mathrm{~g} / 400 \mathrm{gm}$ and $0.512 \%)$. Dalbergia sisoo could not give any yield due to very poor mycelial growth (sawdust of Dalbergia sisoo was very fine as a result there was aeration problems). There were significant differences $(\mathrm{P}<0.05)$ among Alnus nepalensis saw dust and Shorea robusta sawdust. The Shorea robusta could not give good yield and BE was very low. The Biological Efficiency of Alnus nepalensis is agreement with Erkel (2009). He found BE (17.48\%) from oak sawdust, (15.94\%) from Beach sawdust and (15.09\%) 
from poplar sawdust. BE of Shorea robusta was inconsistent with Erkel (2009). This may be due to tight packing and poor aeration and low water holding capacity of fine sawdust because the saw dust of Dalbergia sisoo and Shorea robusta was finer than that of Alnus nepalensis. The difference may also be due to difference in nutritional quality of the different saw dust. The findings are in conformity with some authors who reported broad leaved hard wood sawdust was preferred for commercial production. But sawdust must be coarse and coarse sawdust or wood chips must be mixed in fine sawdust to increase aeration and water holding capacity. As a result mycelium can spread easily and densely.

Different letters along the column indicate significant differences of the mean ( $\mathrm{p}=0.05$ ) according to Duncan Multiple Range Test.

Effect of different type of supplements and control on the yield and biological efficiency of Ganoderma lucidum

Significant differences $(\mathrm{P}<0.05)$ were found among various types of supplements and control (Table 1 and 2). The highest yield $(11.25 \mathrm{~g} / 400 \mathrm{gm})$ and BE (12.19\%) were obtained from Gram flour followed by Rice bran $(9.62 \mathrm{~g} / 400 \mathrm{gm})$ and $10.09 \%$. Rice bran was followed by wheat bran $(8.5 \mathrm{~g} / 400 \mathrm{gm}$ and $7.27 \%$. Corn flour gave lowest yield (7.0 g/400gm) and BE (6.9\%) among supplements.

Control (sawdust without supplements) gave lowest yield (3.12 g/400 gm) and BE (3.91). There were significant difference between substrate with supplements and control in yield and BE. Gram flour showed significance difference with Wheat bran and Corn flour in yield statistically. Although yield showed different among the supplements, gram flour was not different from Rice bran statistically. Similarly wheat bran, corn flour and rice bran were not different statistically. This result was contrast to result obtained by (Erkel, 2009). $\mathrm{He}$ found the highest yield $(63.66 \mathrm{~g} / \mathrm{kg})$ from wheat bran followed by corn bran $(52.37 \mathrm{~g} / \mathrm{kg})$. Rice bran gave the lowest yield among bran $(45.17 \mathrm{~g} / \mathrm{kg})$. He used $20 \%$ of bran but in this study $10 \%$ bran was used. This contrast seems to be resulted from the ratio of supplements. Gram flour showed significant with rice bran, wheat bran and corn flour in biological efficiency. Although biological efficiency showed difference among the supplements, wheat bran was not different from corn flour statistically.

These results suggest that the yield and biological efficiency are different for different substrates.

Different letters along the column indicate significant differences of the mean ( $\mathrm{p}=0.05$ ) according to Duncan Multiple Range Test.

\section{Conclusions}

The effect of various kinds of sawdust and supplements on the yield of Ganoderma lucidum was investigated in this study. As described above, yield and biological efficiency of Ganoderma lucidum varied widely depending on the kind of sawdust and supplements. Therefore it is important to use the proper substrate for the commercial production of G. lucidum. Alnus nepalensis sawdust supplemented with gram flour showed highest yield among all treatments. There was no significant difference between gram flour and rice bran supplement. As rice bran is industrial byproduct and economically cheaper than gram flour, it is recommended to use rice 
O.K. Gurung, U. Budathoki and G. Parajuli / Our Nature (2012) 10: 191-198

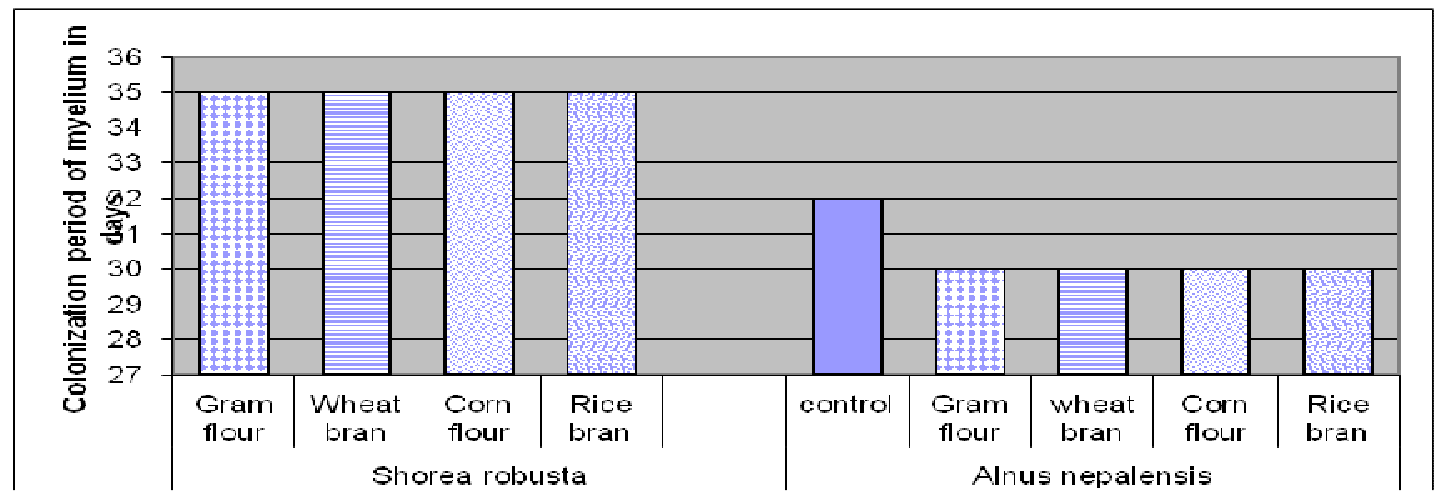

Figure1. Comparison of colonization period

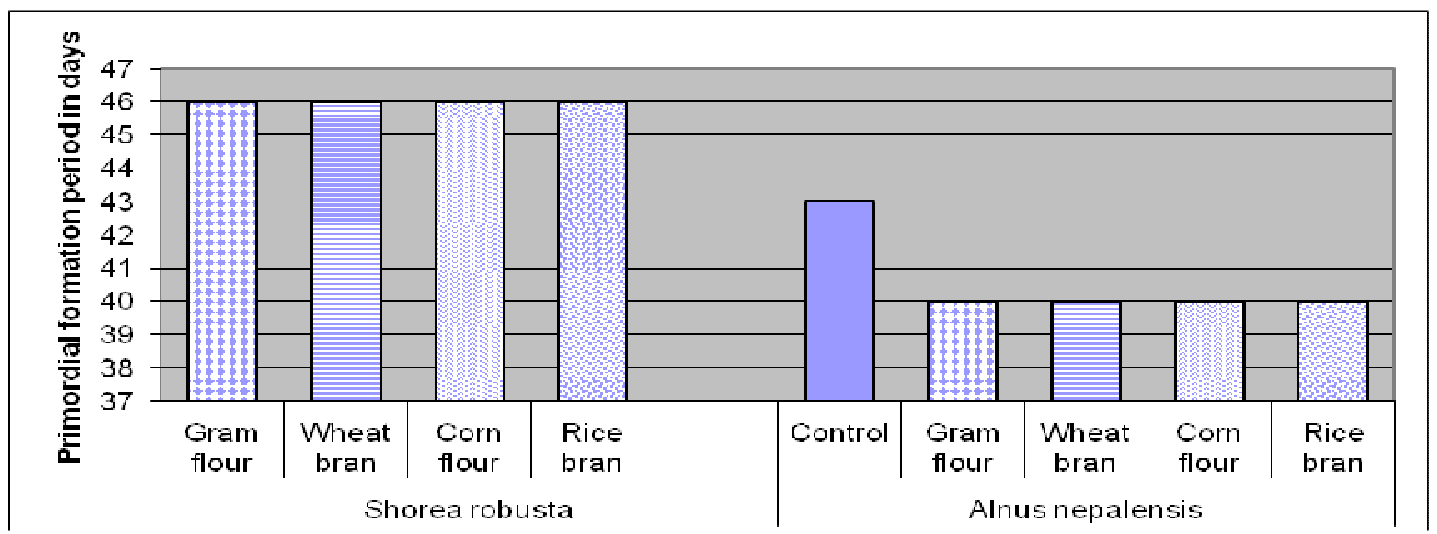

Figure 2. Comparison of primordial formation period

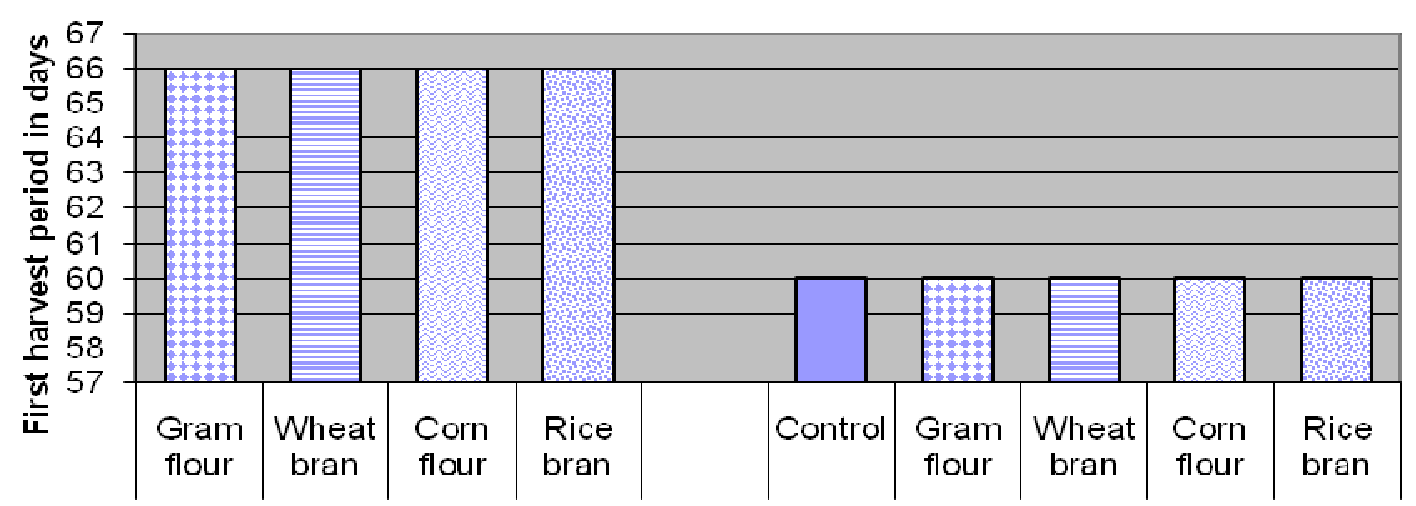

Figure 3. Comparison of first harvest period 
O.K. Gurung, U. Budathoki and G. Parajuli / Our Nature (2012) 10: 191-198

Table 1. effect of various kinds of sawdust on yield and Biological Efficiency of Ganoderma lucidum

\begin{tabular}{|c|c|c|c|c|c|}
\hline sawdust & supplement & Yield g/400gm & mean & $\begin{array}{l}\text { Biological } \\
\text { efficiency }(\%)\end{array}$ & Mean \\
\hline $\begin{array}{l}\text { Shorea robusta } \\
\text { sawdust } \\
\text { (SS) }\end{array}$ & $\begin{array}{l}\text { Control } \\
\text { Gram flour } \\
\text { Wheat bran } \\
\text { Corn flour } \\
\text { Rice bran }\end{array}$ & $\begin{array}{l}0.00^{\mathrm{a}} \\
1.75^{\mathrm{a}} \\
0.00^{\mathrm{a}} \\
0.00^{\mathrm{a}} \\
1.5^{\mathrm{a}}\end{array}$ & $0.65^{b}$ & $\begin{array}{l}0.00^{\mathrm{a}} \\
1.75^{\mathrm{a}} \\
0.00^{\mathrm{a}} \\
0.00^{\mathrm{a}} \\
0.81^{\mathrm{a}}\end{array}$ & $0.512^{b}$ \\
\hline $\begin{array}{l}\text { Alnus nepalensis } \\
\text { sawdust } \\
\text { (AS) }\end{array}$ & $\begin{array}{l}\text { Control } \\
\text { Gram flour } \\
\text { Wheat bran } \\
\text { Corn flour } \\
\text { Rice bran }\end{array}$ & $\begin{array}{l}6.25^{\mathrm{c}} \\
20.75^{\mathrm{a}} \\
17.0^{\mathrm{ab}} \\
14.0^{\mathrm{b}} \\
17.75^{\mathrm{ab}}\end{array}$ & $15.05^{\mathrm{a}}$ & $\begin{array}{l}7.81^{\mathrm{c}} \\
22.62^{\mathrm{a}} \\
14.58^{\mathrm{b}} \\
13.81^{\mathrm{b}} \\
19.37^{\mathrm{a}}\end{array}$ & $15.69^{\mathrm{a}}$ \\
\hline
\end{tabular}

Table 2. Effect of different type of supplement and control on yield and Biological efficiency of Ganoderma lucidum

\begin{tabular}{|c|c|c|c|c|c|}
\hline supplements & Sawdust & Yield (g/400gm) & mean & $\begin{array}{l}\text { Biological } \\
\text { efficiency }(\%)\end{array}$ & mean \\
\hline control & $\begin{array}{l}\text { SS } \\
\text { AS }\end{array}$ & $\begin{array}{l}0.00 \\
6.25\end{array}$ & $3.12^{c}$ & $\begin{array}{l}0.00 \\
7.81\end{array}$ & $3.91^{\mathrm{d}}$ \\
\hline GF & $\begin{array}{l}\text { SS } \\
\text { AS }\end{array}$ & $\begin{array}{l}1.75 \\
20.75\end{array}$ & $11.25^{\mathrm{a}}$ & $\begin{array}{l}1.75 \\
22.62\end{array}$ & $12.19^{\mathrm{a}}$ \\
\hline WB & $\begin{array}{l}\text { SS } \\
\text { AS }\end{array}$ & $\begin{array}{l}0.00 \\
17.00\end{array}$ & $8.50^{b}$ & $\begin{array}{l}0.00 \\
14.58 \\
\end{array}$ & $7.27^{\mathrm{c}}$ \\
\hline $\mathrm{CF}$ & $\begin{array}{l}\text { SS } \\
\text { AS }\end{array}$ & $\begin{array}{l}0.00 \\
14.0\end{array}$ & $7.00^{b}$ & $\begin{array}{l}0.00 \\
13.81\end{array}$ & $6.90^{c}$ \\
\hline RB & $\begin{array}{l}\text { SS } \\
\text { AS }\end{array}$ & $\begin{array}{l}1.5 \\
17.15\end{array}$ & $9.62^{\mathrm{ab}}$ & $\begin{array}{l}0.81 \\
19.37\end{array}$ & $10.09^{b}$ \\
\hline
\end{tabular}

bran as a supplement with $A$. nepalensis sawdust to cultivate Ganoderma lucidum. Wheat bran can be used as an alternative supplement. Supplementation showed positive role in mycelia growth and yield of mushroom. So, supplementation is required for commercial production of Ganoderma lucidum.

\section{References}

Bano, Z., M.N. Shasirekhaandm and S. Rajarathnam 1993. Improvement of the bioconversion of biotransformation efficiencies of the oyster mushroom (Pleurotus sajor-caju) by supplementation of its rice straw with oil seed cakes. Enzyme and Microbial Technology 15: 985-989.
Chang, S.T. and, P.G. Miles 2004. Mushrooms:Cultivation, Nutritional Value, Medicinal effect and Environmental Impact ( $2^{\text {nd }}$ edition) Boca Raton, CRC press.

Erkel, E.I. 2009. The effect of different substrate medium on the yield of Ganoderma lucidum (Fr.) Karst. Journal of Food, Agriculture and Environment 7(3-4): 841-844.

Kwon, H. and B.S. Kim 2004. Mushroom growers' Handbook1; Bag cultivation. In Oyster mushroom Cultivation. Mushworld, Republic of Korea. pp.144-159.

Lee, K.M.., S.Y. Lee and H.Y. Lee 1999. Bistage control of $\mathrm{pH}$ for improving exopolysaccharides production from mycelia of Ganoderma lucidum in an air- lift fermenter. J.Biosci.Bioeng. 88(6): 646-650.

Peksen, A. and G.Yakupoglu 2009. Tea waste as a supplement for the cultivation of Ganoderma 
O.K. Gurung, U. Budathoki and G. Parajuli / Our Nature (2012) 10: 191-198

lucidum. World Journal of Microbiology and Biotechnology 25(4): 611-618.

Plant Pathology Division (PPD) 2007. Cultivation methodology of Red mushroom. In Annul Report (2005-2006). Nepal Agricultural Research Council. pp. 57-59.

Plant Pathology Division (PPD) 2010. Study on cultivation of Red mushroom (Ganoderma lucidum) on bed log of Uttis/Alder (Alnus nepalensis). pp. 69.

Plant Pathology Division (PPD) 2010. Study on cultivation technology of Ganoderma spp. on paddy straw. In Annual Report 2008-2009. Nepal Agricultural Research Council. pp. 66.

Royse, D.J. 1985. Effect of spawn run time and substrate nutrition on yield and size of the Shiitake mushroom. Mycologia 77: 756-762.

Smith, J.E., N.J. Rowan and, R. Sullivan 2002. Medicinal mushrooms: A rapid developing area of biotechnology for cancer therapy and other bioactivities. Biotechnology Letters 24: 18391845.

Staments, P. 2000. Growing gourmet and medicinal mushrooms ( $3^{\text {rd }}$ edition). Ten Speed Press Olimpia, WA.

Wagner, R., D.A. Mitchell, G.L. Sassaki, M.A.L.A. Amazonas and M. Berovic 2003. Current techniques for the cultivation of Ganoderma lucidum for the production of biomass, ganoderic acid and polysaccharides. Food Technol. Biotechnol. 41(4): 371-382.

Wasser, S.P. 2005. Reishi or Ling Zhi (Ganoderma lucidum). Encyclopedia of Dietary Supplements. pp. 603-622.

Yang, F.C. and C.B. Liau 1998. Effect of cultivating conditions on the mycelial growth of Ganoderma lucidum in submerged flask cultures. Bioprocess Engineering 19: 233-236. 